\title{
1 Designing a climate-smart brinjal that can withstand a variety of environmental
} conditions: A perspective

\author{
Bandi Arpitha Shankar \\ Acharya N G Ranga Agricultural University, Tirupati, Andhra Pradesh, India \\ ORCiD: 0000-0002-7077-2677 \\ Email: projectresearch2019@gmail.com
}

\begin{abstract}
Brinjal is a beautiful vegetable crop with strong nutritional properties specifically folate concentration and total chlorogenic acid content. These vitamins and minerals are very much effective in building up the immune system, whilst chlorogenic acid content protects the human body against heart illnesses, liver issues and diabetes. The quantity of these chemicals changes from cultivar to cultivar largely based upon the location of growth and changing environmental circumstances. Many plant breeding strategies are used to alleviate the losses but have proved to be less successful. Whereas the use of molecular markers and other biotechnology technologies have created a road for creating climate smart brinjal with maximum yields and nutritious contents.
\end{abstract}

Keywords: Brinjal, Chlorogenic acid content, Climate smart, Breeding, Molecular markers.

\section{Introduction:}

Vegetables and fruit crops are a major group which are highly sensitive to climatic changes and exhibit varied changes not only in their physiology but also in their reproductive stages and show reduced yields. Climatic changes effect the farmers who grow vegetables and also fruits. Certain climatic changes may include drought, heat, cold, chilling conditions, rainfall, floods, mining and greenhouse gases emission [1]. As known so many crops depend upon climatic conditions and environment to complete their life cycle which includes vegetative stage, reproductive stage and fruit maturity stages which are the most important and vulnerable stages in the entire growth cycle of the crop. Sometimes the lifecycle or the growth stages of several fruits and vegetables are very much altered due to unfavorable climatic changes like dormancy of the seed, improper seedling growth and yield losses where if these climatic changes are in severe form, they may lead the crop towards death by showing some symptoms like drooping, yellowing of leaves, dry stems, dry leaves, withering etc [2].

These climatic changes have drastic effects on the crops by damaging their growth patterns where severe drought conditions would lead to drying of the crops and reduced growth. Lack of water conditions is a serious threat towards agriculture especially incase of fruit and vegetable crops where the crops tend to show certain symptoms. Also, high temperature conditions would affect the crop in different ways like damaging the internal properties of the plants by arresting certain physiological conditions. Also, high temperature conditions above $55^{\circ} \mathrm{C}$ would damage the crops by disturbing the natural cycles in the crop and also reducing the photosynthesis in the plants which in turn plants dies due to lack of proper nourishment [3]. In some cases, like chilling or cold conditions where the temperature falls up to $-2{ }^{\circ} \mathrm{C}$ in chilling conditions and below $5^{\circ} \mathrm{C}-10^{\circ} \mathrm{C}$ in cold conditions which promotes higher production of certain hormones like ethylene which leads to improper growth of the plants, also in some cases chilling conditions would lead to pulp damage or pulp leakage in case of developed or developing fruits which will be a major loss by deteriorating the post-harvest quality. Along with these higher rainfalls cause flooded conditions in which plants are exposed to prolonged water stagnation where these plants lose their rigidity and the fruits become soft and useless for market purpose [4]. Above all certain greenhouse gases and some mining projects would affect the environment conditions which in turn spoil the crop growth environment. These damages caused by improper climatic conditions would not only affect the growth and development of the crops but also change their life cycle patterns which in turn reduces the yield of the crop [5].

Many agriculturally important vegetables and fruits are almost all prone to improper climatic conditions and are able to tolerate up to a certain level. But due to increased changes in the climatic conditions causing severities on the surrounding crop environment would affect the crop in a greater way by leading to the death of the crop [6]. 
47 Brinjal is considered as the most important vegetable due to its high nutritional qualities and easy adaptable nature. 48 These species are the most important members of the family Solanaceae. This brinjal is of different types, shapes and color. Also, the fruit of brinjal can be used in different ways like chutney making, pickles, curries and fries. This fruit of the brinjal is also considered as the King of the vegetables as it occupies a major position as a main attractive dish in several occasions of South India. Apart from this Brinjal is a low calorie and high fiber plant having several health benefits and providing essential nutrients [7].

The peel of brinjal is high in anthocyanins and phenolic compounds which makes it the most important vegetable for eating. Also, several minerals make eggplants very important source for nutrition. This way the most important vegetable crop Brinjal is vital source of mineral, nutrients and fiber which is edible in different ways and can easily grow under normal conditions [8]. In our review we concentrated on the most important vegetable crop i.e., Brinjal and its adjustable nature during unfavorable conditions. The tendency of the brinjal under improper climatic changes is understood carefully and the important steps were considered for making the brinjal a climate smart crop [9].

This crop is highly advantageous due to its unique properties like having less fats which protects the heart, fights cancers, reducing anemia, maintaining bone health and very much useful during pregnancy [10]. But in recent years there are so many questions and discussions on proper growth and yield status of this crop because of improper climatic changes which proves to have a drastic effect on the growth of the crops from old, aged agriculture [11]. These climatic changes if are more than the tolerance level would reduce the usage and importance of traditional breeding methods which could pose a serious threat to the present-day agriculture and a really important problem to the farmers. This study deals with the proper understanding of the response in different stages of the crop towards varying climatic conditions and also the role of climatic changes in altering the nutritional qualities of the crop [12]. The medicinal properties and the other therapeutic properties were also known to be affected due to harsh environmental conditions thereby making the brinjal plants unfit for consumption [13].

\section{Nutrition in Brinjal:}

Brinjal is highly known for its nutritional properties and there a group a minerals, vitamins, carbohydrates and other essential elements in a required quantity for an individual who consume brinjals[14].

Table 1: Nutrition of brinjal (per 100g)[15]

\begin{tabular}{|l|l|l|l|l|l|}
\hline TOTAL ENERGY & AMOUNT & MINERALS & AMOUNT & VITAMINS & AMOUNT \\
\hline Calories & $25 \mathrm{kcal}$ & Calcium & $10 \mathrm{mg}$ & Vitamin A & $1 \mu \mathrm{g}$ \\
\hline Total carbohydrates & $6 \mathrm{~g}$ & Phosphorus & $25 \mathrm{mg}$ & Vitamin C & $2.5 \mathrm{mg}$ \\
& & & & & \\
\hline Total fats & $0.22 \mathrm{~g}$ & Potassium & $230 \mathrm{mg}$ & Vitamin $\mathrm{K}$ & $3.7 \mu \mathrm{g}$ \\
\hline Total proteins & $1 \mathrm{~g}$ & Magnesium & $15 \mathrm{mg}$ & Vitamin E & $0.5 \mu \mathrm{g}$ \\
\hline & & Iron & $0.25 \mathrm{mg}$ & Thiamine & $0.041 \mathrm{mg}$ \\
\hline & & Zinc & $0.19 \mathrm{mg}$ & Folate & $22 \mu \mathrm{g}$ \\
\hline
\end{tabular}

A total of $25 \mathrm{Kcal}$ would be obtained by consuming $100 \mathrm{~g}$ of brinjal fruit where total carbohydrate is more compared to fats and proteins, which is about $6 \mathrm{gm}$ and $0.22 \mathrm{gm}$ of fats which is very less and thus makes the crop a good sources of weight loss. Along with this potassium is the most abundant mineral compared to other minerals in brinjal fruit which is about $230 \mathrm{mg}$ which is very much helpful in protecting against several ailments, whereas zinc is very low compared to other minerals which is about $0.196 \mathrm{mg}$ (Table 1). 
very much helpful in maintaining blood clots without the loss of blood. Whereas Thiamine is present in very less amount compared to other vitamins in brinjal which is about $0.0041 \mathrm{mg}$ other than B complex [18]. Folic acid is the often known as Folate which is the most abundant vitamin in brinjal and is very much helpful for pregnant women. Brinjal known to be very helpful especially for pregnancy due to its several advantages of maintaining the embryo sac and assist in the development of the growing fetus $[19,20]$. This folate content is nearly about $22 \mu \mathrm{g}$ (Table 1) which is more and abundant compared to other members of the Solanaceae family. This presence of important minerals and essential vitamins along with higher amounts of folate makes brinjal a unique crop for nutrition not only for proper health [21].

\section{Effect of climate change on Brinjal:}

Changes in the climate has brough several problems in case of many vegetables and fruits deteriorating the quality and nutrients. Severities in the environmental conditions brought about many changes in the growth stages of several vegetables arresting the growth of young saplings [22]. Especially in case of Brinjal which is a very important vegetable crop in the entire world is very sensitive to the changes in the climate which effects the growth of young seedlings and the yields of the crop [23].

Since brinjal is a very important vegetative used all over the world in different cuisines and plays a major role in important occasions in southern part of India. Also, this vegetable is famous for its taste and varieties. It can be used for making fries, stuffed curries and some continental dishes [24]. In some dishes very small brinjals are preferred which gives good texture and taste to the curry, whereas in some other curries long slender brinjals were preferred and most importantly for making curries short and stout brinjals are used which enhance the taste of the curry. Different colors of brinjal is also a very important consideration for preparing different cuisines as the purple colored brinjal fruits enhance the taste of the dishes compared to light green colored brinjals, because light green colored brinjals are slightly bitter compared to purple color. These light colored brinjals are somewhat similar to that of their wild parents and are almost similar in taste [25].

Different problems arising it climatic changes cause lots of problems in case of brinjal plants and its fruits. In tropical and sub-tropical regions of the world it was observed that the growth of the crop is arrested especially during fruit setting stages due to high temperature conditions [26]. The high temperatures above $55-60{ }^{\circ} \mathrm{C}$ are very problematic as they allow the dropping of the flowers and reduce the capacity of fruit setting. Along with these qualities it was also observed that the taste of the fruits under the influence of high temperature conditions is less and somewhat bitter [27]. The increasing temperature reduces the quality of the fruit by reducing the taste and size of the fruits which makes the fruits unfit for the consumption and there by reduces the economic value of the fruits [28].

Whereas in certain temperate regions where temperature falls below $5^{\circ} \mathrm{C}$ or less than $0{ }^{\circ} \mathrm{C}$ is highly problematic to the brinjal plants as the growth is arrested. Low temperature conditions damage the cells of the crops effecting the tissues of several plants and thereby reducing the nutritional status of the crops. The cold or chilling conditions of the crops alter the fruit growth by reducing the size of the fruits and makes them unripe and very unfit for consumption [29]. In some cases, it was observed thar the flesh in the fruits become hard and not fully developed. Thus, low temperatures play a major role in spoiling the entire cropping cycle of the plans and arresting the growth thereby leading to the loss of nutritional qualities of the plants [30].

Along with these severe climatic changes rainfall and floods are very much dangerous because they cause the uprooting of the crops from ground level which will be more disadvantageous as the entire crop is lost due to heavy water conditions [31,32]. In some cases, water stagnation and improper drainage conditions causes severe damage to the crops by cause rots in the root regions and stem regions. Leaves of the waterlogged areas are pale in color and underdeveloped which in turn would affect the photosynthesis and thereby reduces the nutrition in the plants through which the growth of the plants is arrested [33]. Also, greenhouse gas emissions from industries along with certain gas emission from other crop fields is also causing a major problem to the growth of the plants. The crops effected by gases would likely tend to become pale yellow to yellowish in color and show symptoms of 
stunting and drooping of the leaves and stems. All the above conditions would affect the growth of brinjal plants by deteriorating the quality of the fruits or leading to the death of the plants under severe climatic changes [34].

Table 2: Effect of climate change in Eggplant [35]

\begin{tabular}{|l|l|}
\hline Climate change & Percent effected \\
\hline Rainfall and flooding & $38 \%$ \\
\hline High temperatures & $29 \%$ \\
\hline Chilling temperatures & $12 \%$ \\
\hline Snow falls and hail storms & $3 \%$ \\
\hline Greenhouse gases & $17 \%$ \\
\hline
\end{tabular}

Brinjal is mostly affected by rainfall and flooding conditions where the percent effected is maximum and is about $38 \%$ and causes severe damage to the growing plants. This rainfall causes severe drooping of the leaves and stem of the crops, even though the fruits formed would not stand to the plants but gets detached and fall off from the plants. This is the major havoc caused by rainfall along with certain smuts and rots. Whereas, this brinjal is not habituated or cultivated in extreme low temperatures, but if any case these plants when exposed to lower temperatures would damage the plants by causing freeze injury and hardening the pulp of the fruits. This reduces the growing conditions of the crops and effects the crops at all stages by reducing the nutrition accumulation and retarding certain important plant growth pathways. The other climatic changes are also effective in the brinjal plants but causes low yields under extreme conditions. Thus, brinjal being a king of vegetable crops is damaged or mostly effected by drastic changes in the climate where it shows certain symptoms like rots, smuts, underdeveloped fruits and entire crop damage.

\section{Brinjal Genome:}

Brinjal is commonly known as Eggplant due to its oval shape and difference in size and it is so called in US, Australia and New Zealand, it is also called as aubergine in parts of UK, Ireland and Western Europe, whereas it is called brinjal in Asia and South Africa [36]. This plant is mostly known for its edible properties and its nutritional qualities. This vegetable crop belongs to the family Solanaceae and the fruit is known as Berry due to the arrangement of the seeds in the fruits [37].

The total set of genomes found in a particular plants or organisms is known to be genome size of the particular organism. The genome size of a particular organism can be analyzed as a single copy of entire set of genomes and can be well understood using picograms [38]. The maximum amount of DNA present in the organism together us called a genome and the larger the genome size the larger the time is taken for sequencing and replication and the smaller size of the genome takes very less time to complete the sequencing and replication where sequencing helps to understand the arrangement of nucleotides in a genome [39].

There are so many sequencing methods available so far and the methods are really quick. Compared to the old sanger's method newest next generation methods are very much appropriate in giving the results through which the arrangement or the sequence of the nucleotides is clearly understood and also these methods pave way towards highly useful genome editing techniques which helps to alter the genomes of a particular organisms and making it more beneficial to the surrounding environment [40,41]. These genome editing techniques can be done using different enzymes, buffers, vectors etc. and its main aim is to resolve the areas where the genomes are not proper and which cause disease can be resolved so that alteration can happen and is highly beneficial to the humans as well. This mechanism of genome editing is possible in variety of organisms and species [42].

As known brinjal is a very important vegetable crop all over the world due to its taste and especially colors and different shapes this vegetable occupies a main role in vegetable kingdom and so-called king of the vegetables [43]. Therefore, proper studying and understanding the genomes of this crop is very much important so that the nutritional qualities of this crop may be enhanced and can be very much beneficial for consumption. Also, the 
different genes that are responsible and express during different stress conditions [44]. Certain genes like HSP's, WRKY, MYB etc. are highly responsive under serious heat conditions like temperatures above $50 \mathrm{oC}$. Also, certain genes like CAT and PPO genes are highly responsive during extremely lower temperatures and chilling conditions. Whereas under saline conditions certain genes like SOS, KAT 1 are high responsive and are upregulated under stress conditions [45]. The above genes that are responsive to heat, salt and low temperature conditions were also observed in some members of the Solanaceae family. These genes are known to be upregulated in certain crops like chili peppers, tomatoes etc[46].

Like tomatoes and chilies which share the same family with brinjal where brinjal is an autogamous diploid having 12 chromosomes i.e., $2 n=24$, where the maximum estimated genome size of haploids is about $1.21 \mathrm{~Gb}[47,48]$. Whereas the bell peppers which belong to the same family have the genome sizes more than brinjal which is about $3.5 \mathrm{~Gb}$ where these genomes contain mostly repetitive elements which occupies more than $80 \%$ of the total genome of the bell peppers [49]. Also, this important crop Brinjal is having nearly 560 accession specific families having more than 1000 genes out of which nearly 111 genes are functionally annotated [50].

Therefore, the brinjal which was studied extensively has several gene families where certain genes are shared with the members of the family. These studies help one to understand the importance of gene sequencing and genome editing for the enhancement of nutritional qualities in the plants and also developing brinjal varieties that are highly tolerant to different stresses and making them capable to tolerate differences in climatic conditions through which smart crops [51].

\section{Organellar genomes of eggplant:}

Along with nuclear DNA certain amounts of organellar genomes are known to be present in any plant and are known to play important roles in hereditary. These genomes are well known as extracellular genes and are present outside the chromosomes in certain cell organelles. The plant cell is composed of several organisms which play major important roles in the functioning and the development of the cells as well as the entire organism [52]. Some of these organelles are known to carry certain amount of genetic matter which is very much useful in understanding the hereditary nature of the organisms. The genome sizes of these organelles are very much less compared to the nuclear DNA but are known to be powerful in gene transfer from one generation to next generation. Though there are many cell organelles like Endoplasmic reticulum, Golgi apparatus, vacuoles, Peroxisomes etc., these two organelles play a vital role in maternal inheritance due to the presence of small amounts of genetic material that is transferrable from one generation to another generation [53].

Usually, the genome sizes of these organellar DNA is very small which is about 25- 20,000 genomes per cell and are very neatly arranged in an organized manner. It was observed that the complete mitochondrial genome of eggplant is about 498,136 bp, linear along with $4 \mathrm{rRNAs}$ and $30 \mathrm{tRNAs}$. This entire sequencing of eggplant genome was done by using next generation sequencing method [54]. These sequences were also known for their GC content which is around $44 \%$ which is a really good amount for proper bondage between the bases of the genetic material. After proper sequencing of the mitochondrial genome, it was also cross checked using phylogenetic tree by comparing the genomes of brinjal. It was observed that the mitochondrial genomes eggplant was almost all similar to that of the potato and tomato belonging to the same family [55].

It was also observed that the complete chloroplast genomes of eggplant were around 26,000 bp which was divided into large copy and small single copy. Also, the GC content of the mitochondrial genome was known to be about $38 \%$ which was a good amount for maintaining stability between the bonds. These complete chloroplast genomes were collected from whole genome sequencing project from which the sequences were retrieved, and the sequences were properly filtered by Blast $\mathrm{n}$, which is a nucleotide blast where the similarities between the sequences were searched $[55,56]$. The chloroplast genomes that were generated from the eggplant were compared to that of the chloroplast genomes belonging to their species in the same family. It was observed that the sequences of eggplant are nearly similar to the sequences obtained from solanum nigrum which is a European night shade plant $[57,58]$. 
214 This transfer of organellar genomes is mostly maternal, sometimes paternal and rarely bi-parental. The study of 215 these organellar genomes has gained much importance in the recent years due to their importance in inheritance 216 and their effective functions [59]. It was also known that these genomes replicate in a semiconservative way proving 217 that there is proper exchange of segments in between the genomes. Therefor these organellar genomes paly major 218 important roles in the proper transfer of information from one generation to next generation. Also, these studies 219 are going on extensively for different plant under Solanaceae like tomato, chilies, potatoes, different peppers etc. to observe the important characters in organellar genomes of eggplant and their roles in maintaining the nutrient qualities of the plants under adverse climatic conditions [60].

\section{Challenges, Priorities and Prospect of Plant Breeding in Eggplant (Limitations of Traditional Eggplant Breeding)}

Brinjal is a very important crop of Indian culture as it plays a major role in many auspicious events in Southern part of India. The vegetarian meals in Indian ceremonies include Brinjal as main dish as it is considered a King of vegetable crop [61]. The fruits of eggplants were known to contain low fats and can be used as low- diet for extensive weight loss. Along with these properties eggplants are known to reduce the risk of heart strokes and helps in controlling the blood sugar levels [62].

The growth of eggplants is normal in case pf traditional breeding methods compared to tat of the non-conventional breeding methods where the yields are expected to be more. Brinjal can be well grown in almost all the soils like sandy loams, clay loams, silt loams etc., but clay loams are preferred mostly. This crop usually takes 5 months to complete fruiting and the maturity of the fruits will be completed at the end of 5 months. To obtain higher yields the soils are to be well maintained, well drained and are to be fertile for proper yields where the $\mathrm{pH}$ of the soil should be in between 5.0-6.0[63].

The germination of the seeds and the fruit setting stages of brinjal are the most sensitive growth stages that are most vulnerable to climatic changes. Mostly the sowing of this crop is done in two seasons one in summers and other is early winters till spring[64]. These seasons are ideal for proper growth and development of the crops. Irrigations should be given every alternative day before the soil becomes very dry. A maximum of $60 \mathrm{~cm}$ gap should be given between the seeds of brinjal for proper growth of the plants so that the plants occupy required space for extending their stems. Whereas 300-500 gm of seeds is required for one acre of land. Only high-quality seeds that are previously treated with fungicides should be used for sowing[65].

Eggplants are very much sensitive to biotic and abiotic stresses to mitigate these losses several fertilizers, fungicides and pesticides are used at each and every stage of the crop to increase the yields. But the usage of these harmful chemicals has caused severe problems in plants and ultimately humans. The continuous use of chemicals causes loss of soil nutrients and sometimes effect the growth of soil microbes [66].

In ancient times to reduce these losses traditional methods were employed for proper growth and development of the crops. But the application of traditional breeding methods is quite problematic and a lot time taking. Also, there were not really promising yields after he usage of the traditional plant breeding methods. Traditional plant breeding includes a series of several steps right from the beginning of selecting the parent plants up to the release of new varieties. Although there are several ways in which eggplants are affected by the environment certain crops like rice release methane into the environment which causes severe damage to the air quality thereby effecting the eggplant crops. Also, there are several other reasons for which the changes in the climatic conditions are adverse, all these account tot eh improper productivity of the crops [64,65].

It was observed that the normal temperature conditions for egg plant crop is around $250 \mathrm{C}$ where this temperature is optimum for germination and well growth of the crops. But due to changes in the climatic conditions which causes increased heat i.e., more than $450 \mathrm{C}$ is problematic for germination, flower germination as well as fruit development. Also, it was observed that the fruits that are set during high heat conditions are lack of taste and somewhat bitter than usual. Sometimes the eggplant fruits are less developed or show smaller sizes compared to 
the actual size of the fruit. Under such circumstances sowing of crop in the late season or using heat tolerant hybrids as an alternative is advised under traditional breeding methods to reduce the damages caused by high temperature conditions [67].

In some places with low temperature conditions i.e., below 10C where the proper conditions for growth is less and the plants show wilting symptoms. Also, the growth of the crops are arrested where the plants exhibit stunting and underdeveloped stems and fruits. In certain rainfall areas the plants show certain rotting symptoms where the fruits of the eggplants become soft and oozes water from inside. In such cases of low temperatures and rainfall conditions the crops are sown in the later season, mixed cropping is employed sometimes or growing of the eggplants in green houses under controlled environmental conditions is the possible way to fix the changes in the climate [67].

Not only these effects but also drought causes severe damage to the crops and causes severe yield losses where the drought tolerant varieties that are developed through plant breeding are used for protecting the crops from the harmful effects of the climate [68]. Although these solutions of employing certain plant breeding techniques under adverse climatic conditions is not pretty much successful due to its laborious methods and time-consuming procedures. But following these methods like late sowing of the crops, early sowing of the crops before the season, short duration crops etc. would reduce the drastic yield loss effects caused by climate changes in brinjal and other crops belonging to the same family [69].

Table 3: Eggplant varieties suitable for adverse climatic changes[70]

\begin{tabular}{|l|l|}
\hline Eggplant Varieties & Tolerance \\
\hline Arka Harshitha & Tolerant to high temperatures \\
\hline Arka Neelanchal Shyama & Early variety suitable for rabi season \\
\hline Pusa Kranti & Suitable for high and very low temperatures \\
\hline Pusa Syamala & Suitable for waterlogging conditions \\
\hline Niranjan Bhata & Resistant to insects and pests \\
\hline Diamond eggplants (Russian) & Highly drought tolerant \\
\hline
\end{tabular}

Different eggplant varieties are known to possess different characters suitable for different climatic conditions. These varieties are derived from extensive plant breeding techniques where they are tested both in field and laboratory conditions. There are some varieties (Table 3) where they are tolerant to high and low temperature conditions like Arka Harshitha, Arka Neelanchal and Pusa Kranthi. Also, some varieties like Pusa Symala and diamond eggplants are tolerant to waterlogging and drought conditions respectively. The most important variety like Niranjan Bhata was known for its tolerance against pests and diseases where it does not show any yield losses under severe disease and pest attack like other brinjal varieties. Therefore, proper cultivation of certain important eggplant varieties which are able to tolerate climatic changes is very much important for the development of climate smart brinjal.

\section{Genetic Resources of Eggplant: Diversity, Characterization and Utilization}

Solanum melongena which is the most important and famous crop in almost every part of India. In general, this plant requires warm climatic conditions for proper seed germination, seedling growth, flower development, fruit setting and fruit maturation up to physiological harvest which takes nearly about 5-6 months' time[71]. The soil should always be well drained to avoid the fungus invasion and all the rots which would reduce the fruiting of the plants. In general eggplant can withstand a temperature up to $40 \mathrm{oC}$ but not more than that, however plants if exposed would show certain symptoms like discoloration and drying flesh of the fruits. This makes the plants look frowzy and they do not appear well. Depending upon these conditions different varieties are used in different areas depending upon the changes in the climatic conditions of that particular area[72].

\section{Table 4: Popular varieties in different regions of India[73]}




\begin{tabular}{|l|l|}
\hline North Indian Region & Pusa Barsati, Pusa Anmol, Pusa Syamala \\
\hline South Indian Region & APAU Shyamala, Co-1, MDU 1 \\
\hline East Indian Region & Swarna Shree, Swarna Mani \\
\hline West Indian Region & Janak, BSS-793 \\
\hline
\end{tabular}
298 important aspects like soil health, seed vigor etc. The popular varieties like Pusa Barsat, Pusa Syamala is grown in 299 most of the areas of North India(Table 4) whereas APAU shyamala along with other varieties is most common in 300 South India and Swarna Shree and Janak are the important varieties of East India and Western India respectively. 301 These varieties are so cultivated depending upon the areas of high productivity due to less chances of losing yields and also the tolerant nature of these varieties towards climatic changes is maximum.

This eggplant is mainly known for its nutrient content, vitamins especially folate and importantly chlorogenic acid. The contents of these economically important vegetable crop is of high nutritional values and is suitable for weight loss programme. This chlorogenic acid is very much useful for maintaining sound health especially reducing the risks of hear attacks, blocks insulin and reduces the accumulation of fats in liver.

Table 5:Total chlorogenic acid content in important cultivars of eggplant [74]

\begin{tabular}{|l|l|}
\hline Varieties of eggplants & CGC content $\mathbf{( g / k g )}$ \\
\hline Scarlet variety of eggplant & 1.03 \\
\hline S. Aculeatum & 1.03 \\
\hline S.macrocarpon & 1.99 \\
\hline S. dasyphyllum & 4.9 \\
\hline Gboma variety of eggplant & 2.5 \\
\hline
\end{tabular}

Different varieties of eggplant show differences in the chlorogenic acid contents where the maximum amount of chlorogenic acid is found in S. dasyphyllum (Table 5) variety of eggplant which is the native of middle eastern countries and is very beneficial for health due to its high chlorogenic acid content which is proven to have several nutritional characters. Whereas, the Gboma variety of eggplant which is native to south Africa is also having good amount of chlorogenic acid which is about $2.5 \mathrm{~g} / \mathrm{kg}$ (Table 5) which is also a very beneficial for human health. The rest of the important varieties are also having chlorogenic acid but in less amounts i.e., nearly $2 \mathrm{~g} / \mathrm{kg}$.

Due to its several important characters like nutritional status, low fats, high chlorogenic acid contents, vitamins, minerals etc. eggplant is a wonderful vegetable crop which should be involved in our daily food intake. Consumption of eggplants on a regular basis has proven benefits like maintaining good body shape and health of the person and also proper liver functioning and most importantly keeps heart risks at bay. But the cultivation of these plants under unfavorable conditions is quite a problem which may result in heat stress, cold stresses, damages caused by through rainfall and flooding and harmful gaseous effects.

To avoid all these unne4cesary circumstances or yield losses of the crop, proper care should be taken for sowing of the suitable variety under suitable conditions and proper soil maintenance.

\section{Table 6: Different climatic changes and tolerant cultivars [75]}

\begin{tabular}{|l|l|}
\hline Climate changes & Cultivars \\
\hline Heat tolerant & Nadia, Florida Highbush, Traviata \\
\hline Cold tolerant & Rashika, Sheetal, HABH-8 \\
\hline Rainfall and waterlogging & CO-1, CO-2, MDU, PKM-1 \\
\hline Drought tolerant & Azad kranthi, Azad Keshav, Pusa Hybrid 5 \\
\hline
\end{tabular}

The most important climate changes in any area is heat, cold, rainfall and drought where the use of tolerant varieties like Nadia, Traviata etc., for heat, Sheetal, Rashika etc., for cold conditions, CO-1, CO-2 etc., under rainfall conditions and Azad kranthi, Azad Keshav etc., for drought is very much advisable to avoid all the yield losses caused by such unfavorable environmental conditions. 
327 Therefore different varieties of eggplants have tolerance towards different climatic changes, theses varieties are 328 developed by prolonged breeding methods where the trails are properly conducted and time taking procedures were followed. Out of many available cultivars of eggplant present in India and around the world having several medicinal and therapeutic properties along with high chlorogenic acid content and folate contents and quality fruits with proper yields and pretty much tolerant to changes in climatic conditions making this crop climate smart [76].

\section{Development and Application of DNA Markers in Context to Brinjal}

DNA markers are very useful and very much important segments of DNA where they were used to detect the polymorphisms different genotypes for a particular sequence in a gene pool or a large population. It helps to identify the exact location of the known segment of DNA which can be used as a reference sequence for important studies [77].

In case of crop improvement programmes with respect to the time taking breeding methods DNA markers play a major role in identifying the purity of the seeds, hybrid testing, diversity studies, linkage analysis, QTL mapping and MAS studies. Also, markers help one to understand the differences clearly between the available gene and genes of interest. All these studies are very much important for understanding the nature of the hybrid variety that will be useful in crop improvement [78].

Especially in case of eggplant several DNA markers were used to assess the genetic variability and diversity studies to isolate the important varieties that are suitable for crop improvement programmes.

Table 7: Molecular markers: Use in Eggplant [79].

\begin{tabular}{|l|l|}
\hline Markers & Usage in eggplant \\
\hline SNP & $\begin{array}{l}\text { Used in genome wide analysis and helps in identifying } \\
\text { or differentiating plant varieties. }\end{array}$ \\
\hline SSR & $\begin{array}{l}\text { Maximum genomic abundance was observed along } \\
\text { with comparative genomic analysis studies }\end{array}$ \\
\hline EST-SSR & $\begin{array}{l}\text { These are detected in non-coding regions, useful in } \\
\text { gene targeting and marker assisted selection. }\end{array}$ \\
\hline RAPD & $\begin{array}{l}\text { These microsatellites are useful in identity studies of } \\
\text { strains, genes and parents. }\end{array}$ \\
\hline
\end{tabular}

Different markers were used in eggplant studies to achieve proper yields and hybrids in plant breeding programme. These markers one way or the other are very much useful in multitasking in plant breeding programme in a way of identifying the unique characters in plants of same species along with understanding proper parentage of the released hybrids. Mostly SSR's and RAPD markers are well used in case of eggplant studies where SSRs are useful in comparative genomic studies as well as RAPD markers identify genomic variability between genotypes (Table 7). Along with these markers other types like SNP's, EST-SSR's and ISSR's were also well used in studying different strains and MAS studies in different species or in between the varieties of the same plants especially for genomic studies in case of eggplant.

\section{Genome-Wide Approaches}

The variations in the genomes are very well understood using genome wide approaches. This is achieved by properly scanning the entire genomes of a particular organism to identify any genes that are disease causing or any malformations in the plants so that the alterations can be made to protect the plants from the diseases and death. These approaches are gaining much importance theses days due to their accuracy and benefits in plant breeding programmes, where several losses can be reduced [80]. These studies are done to identify the desirable 
and undesirable traits of the plants so that only the desirable traits are concentrated to the next generation to achieve maximum yields. This is highly beneficial as the unwanted traits were eliminated and plants can be protected from unwanted diseases. The characters of the plants can be observed both phenotypically and genotypically so that the nature of the plants was well understood [81].

This technique has gained much importance because of its unique nature in identifying the cause of the diseases which may be known or new. By studying these genes that are responsible for causing such diseases are altered and the transfer of diseases from one generation to the next generations is greatly arrested so that the plants are protected, yield losses are greatly reduced and ultimately very much beneficial to humans [80,81]. In general, these studies are based on population studies where there were comparisons between different species of same plant populations and their growth characteristics were carefully observed. Most importantly these studies are dealt with the usage of linkage disequilibrium map and association mapping along with knowing the ancestry of particular species and studying their wild relatives. The quantitative percentages of the populations along with the knowledge of ancestors is the very important step for genome wide studies which is achieved by comparing the individuals between two populations or within the same population.

Genome wide studies especially in case of egg plant which contain more than 1500 species is well known for its different types based on shapes and colours is very much popular with its wild relatives. Out of all the cultivars in brinjal three are of main importance which are common brinjal S.melongena which is round, egg shaped plants which are round var.esculentum and small in shape and also long, slender fruits var.depressum are well known varieties having many important characters [82].

These studies should be done properly to understand the diversity studies of the genotypes, ancestral characters analysis, population studies and especially sequencing of the eggplant genome. With the help of this sequencing the eggplant genotypes the entire genes were studied carefully so that any unwanted or undesired segment of genes can be improvised through genetic engineering techniques and molecular tools which can make the plants resistant towards the undesirable disease conditions. Therefore it was well understood that the genome wide studies are very much important in identifying and altering the genes that cause severe damage to the crop by yield reductions in plants which can be altered by using molecular biotechnology approaches [83].

\section{Transcriptomic Approaches:}

The total set of RNAs in a particular cell is called its transcriptome. The proper understanding of the transcriptomes is very much important in all the living organisms especially in vegetables. To achieve climate smart eggplants in agriculture proper understanding of the genes that are expressed in different conditions of the plant is very much important to achieve maximum yields and to reduce maximum losses [84].

The transcriptomic analysis is a hybridization technique and works with the help of sequence-based approach where DNA microarrays were involved to detect the genes that are compared with other genes for further analysis. This is the major step for hybridization where many genes were compared at a time and the useful genes were recorded for further usage [85]. Whereas in sequence-based approaches multiple sequences or two sequences are compared so that the similarities between the sequences can be understood. This can be done using multiple sequence alignment and Blast software from Clustal omega and NCBI respectively. The mRNA sequences can be collected from the NCBI of all the species of eggplants where all the sequences can be compared to understand the expressions of genes [86].

Especially in case of eggplant which is the most important vegetable crop having several nutritional properties, proper analysis of genes and studying their functions id very much important [87]. The expressions of different genes under different stresses are to be observed carefully so that the growth of the pants can be estimated. Since eggplant is not tolerant to extreme high or low temperatures where certain genes like WRKY and CAT are responsive respectively [88]. The regulation of these genes would help the plant from unfavorable conditions. These genes protect the plants up to a certain level by controlling the reduced yields and death of the plants. Along with theses genes some other genes like DREB and SmADC genes were responsive under severe drought 
conditions thereby protecting the plants from maximum yield losses and death which is possible only when the genes are upregulated [89]. Therefore, this study of RNA expression for plant protection is Transcription profiling or expression profiling through which different functions of different gees can be made known along with the responses of the genes during unfavorable climatic conditions can be analyzed. This knowledge of differential expression levels of the genes under different environmental conditions are analyzed to protect the plants from severe yield losses [90].

\section{Conclusions and Future Prospects:}

Brinjal which is also known as the King of vegetables was a perennial, herbaceous and tropical plant with a height of 80-100 cms when fully fruited and having a short lifecycle of 5-6 months has a smooth skinned berry fruit with many seeds is used as a famous dish in Indian occasions due to its different sizes, shapes and colors.

This fruit is very famous for its nutritional properties which help to maintain good heart health, liver health, maintaining proper body weight, reducing diabetes and many others. Especially the fruits of eggplants contain maximum amounts of minerals and vitamins where folate is abundant of all. This folate is highly useful for pregnant women as it helps in maintaining the amniotic fluid and aids in protecting the growing embryo. Along with these it also contains many polyphenols and very important compound called chlorogenic acid which has several health benefits. This CGC varies from one cultivar to another cultivar which also depends upon the climatic conditions.

Climate plays a major role in proper growth and development of all the plants especially in vegetables the sowing season and the climatic conditions are very important to obtain maximum yields. But due to increasing pollutions and global warmings there is a drastic change in the climate which makes the crops susceptible and leads to death. There are several climatic changes which influence the growth of the plants in which high and low temperature conditions, drought conditions, rainfall and water logging conditions and release of harmful gases into the environment. All these conditions create many problems for cropping and thereby reduce the yields. Eggplant being very much sensitive to extreme climatic changes shows drastic yield losses when exposed to a longer period of time. Although several breeding programmes are employed to reduce the losses caused by climatic changes in eggplant, they are not very successful due to time consuming methods and high labor requirements. These methods did not solve the problems completely but help in maintain the plant growth to a certain level.

To avoid these losses and to save money and time new approaches that are more advanced compared to breeding programmes like molecular breeding approaches and biotechnology were employed. These studies help to understand the sequences of the entire genome of the plants so that any unwanted gens can be altered or removed which can protect the plants and thereby maintain the yields. Also, certain methods of molecular breeding were also employed to escape the harsh environmental conditioned and the detailed phenotypic and genotypic characters were studied to protect the plant from death.

\section{Future Prospects:}

1. Developing high yielding varieties with good amount of chlorogenic acid.

2. Development of elite lines

3. Development to new hybrids with multiple stress responsiveness

4. Increased nutritional qualities in the fruits

5. Encouraging transgenic crops that are both biotic and abiotic stress tolerant

6. Employing advanced crop management practices with improved molecular biology tools

7. Designing stress responsive genes that are heritable to generations

8. Developing cost effective methods of plant growth

9. Designing climate adaptable varieties

10. Promoting good health at affordable price

Since eggplant being a wonderful vegetable crop having several nutritional qualities is well known for its high folate and chlorogenic acid contents which are highly beneficial for human consumptions so that several body 
functions are regulated and maintained. These nutrients help in protecting the human health and also helps in regulating the wight of the body. But the yields of eggplants are reduced drastically duet to severe climatic changes by which the yields of the crops are reduced greatly. Many plant breeding programmes accompanied by molecular markers and biotechnology tools would help to maintain yielding of the crops and make the crops tolerant to different stress conditions up to a certain level so that the crops will be protected but do not die. Considering all these nutritional qualities of eggplant the protection of the plant and maintaining its productivity in the present situation where climatic conditions are changing drastically so that their yields may not be reduced and the nutrition of the crops can be maintained up to generations so that the climate smart eggplants can be produced and supplied to the farmers, where these cultivars would be able to withstand changes in the environment.

\section{References:}

1. Kaushik, P., Kumar, P., Kumar, S., others, 2020. Enhancement of chlorogenic content of the eggplant fruit with eggplant hydroxycinnamoyl CoA-quinate transferase gene via novel agroinfiltration protocol. Pharmacognosy Magazine 16, 450.

2. Kaushik, P., Plazas, M., Prohens, J., Vilanova, S., Gramazio, P., 2018. Diallel genetic analysis for multiple traits in eggplant and assessment of genetic distances for predicting hybrids performance. Plos One 13, e0199943.

3. Kaushik, P., Saini, D.K., 2019. Sequence analysis and homology modelling of SmHQT protein, a key player in chlorogenic acid pathway of eggplant. bioRxiv 599282.

4. Saini, D.K., Kaushik, P., 2019. Visiting eggplant from a biotechnological perspective: A review. Scientia Horticulturae 253, 327-340.

5. Sharma, M., Kaushik, P., 2021a. Breeding for Root-Knot Nematode Resistance in Eggplant: Progress and Prospects.

6. Sharma, M., Kaushik, P., 2021b. Biochemical Composition of Eggplant Fruits: A Review. Applied Sciences 11, 7078.

7. Sharma, M., Saini, I., Kaushik, P., Al Dawsari, M.M., Al Balawi, T., Alam, P., 2021. Mycorrhizal Fungi and Pseudomonas fluorescens Application Reduces Root-Knot Nematode (Meloidogyne javanica) Infestation in Eggplant. Saudi Journal of Biological Sciences.

8. Yadav, V.K., Singh, R., Jha, R.K., Kaushik, P., others, 2020. Biochemical variability of eggplant peel among Indian cultivars. Indian Journal of Biochemistry and Biophysics (IJBB) 57, 634-637.

9. Brar, N.S., Kumar, T., Kaushik, P., 2020a. Integration of technologies under climate change for profitability in vegetable cultivation: an outlook.

10. Brar, N.S., Saini, D.K., Kaushik, P., Chauhan, J., Kamboj, N.K., 2020b. Directing for higher seed production in vegetables. Agronomy-Climate Change \& Food Security 55.

11. Malhi, G.S., Kaur, M., Kaushik, P., 2021. Impact of climate change on agriculture and its mitigation strategies: A review. Sustainability 13, 1318.

12. Sharma, V., Saini, D.K., Kumar, A., Kesh, H., Kaushik, P., 2020. Breeding for Biofortification Traits in Rice: Means to Eradicate Hidden Hunger. Agronomy-Climate Change \& Food Security 35.

13. Singh, H., Sethi, S., Kaushik, P., Fulford, A., 2020. Grafting vegetables for mitigating environmental stresses under climate change: a review. Journal of Water and Climate Change 11, 1784-1797.

14. Kumar, A., Kaushik, P., 2021. Heat Stress and its Impact on Plant Function: An Update.

15. Malhi, G.S., Kaur, M., Kaushik, P., Alyemeni, M.N., Alsahli, A.A., Ahmad, P., 2021. Arbuscular mycorrhiza in combating abiotic stresses in vegetables: An eco-friendly approach. Saudi Journal of Biological Sciences 28, 1465.

16. Mehmood, S., Khan, A.A., Shi, F., Tahir, M., Sultan, T., Munis, M.F.H., Kaushik, P., Alyemeni, M.N., Chaudhary, H.J., 2021. Alleviation of salt stress in wheat seedlings via multifunctional Bacillus aryabhattai PM34: an in-vitro study. Sustainability 13, 8030. 
17. Priyanka, V., Goel, N., Dhaliwal, I., Sharma, M., Kumar, R., Kaushik, P., 2021. Epigenetics: A Key to Comprehending Biotic and Abiotic Stress Tolerance in Family Poaceae.

18. Virga, G.; Licata, M.; Consentino, B.B.; Tuttolomondo, T.; Sabatino, L.; Leto, C.; La Bella, S. Agromorphological characterization of sicilian chili pepper accessions for ornamental purposes. Plants 2020, $9,1400$.

19. Bhandari, H.; Bhanu, A.; Srivastava, K.; Singh, M.; Shreya, H.A. Assessment of genetic diversity in crop plants-an overview. Adv. Plants Agric. Res. 2017, 7, 00255.

20. European Commission. Organic Farming in the EU-A Fast Growing Sector; Agriculture and Rural Development, Ed.; European Commission: Brussels, Belgium, 2019; p. 12.

21. Chatzisymeon, E.; Foteinis, S.; Borthwick, A.G.L. Life cycle assessment of the environmental performance of conventional and organic methods of open field pepper cultivation system. Int. J. Life Cycle Assess. 2017, 22, 896-908.

22. Abu, S.; Chandra, U.; Das, S.; Chettri, D. Advancements in Agriculture Strategies and Environmental Impact: A Review; SSRN. 2020, p. 15.

23. Trovato, M.R.; Nocera, F.; Giuffrida, S. Life-Cycle Assessment and Monetary Measurements for the Carbon Footprint Reduction of Public Buildings. Sustainability 2020, 12, 3460

24. Del Borghi, A.; Moreschi, L.; Gallo, M. 3-Life Cycle Assessment in the Food Industry. In The Interaction of Food Industry and Environment; Galanakis, C., Ed.; Academic Press: Cambridge, MA, USA, 2021; pp. 63-118.

25. Coltro, L.; Karaski, T.U. Environmental indicators of banana production in Brazil: Cavendish and Prata varieties. J. Clean. Product. 2019, 207, 363-378.

26. Zhu, Z.; Jia, Z.; Peng, L.; Chen, Q.; He, L.; Jiang, Y.; Ge, S. Life cycle assessment of conventional and organic apple production systems in China. J. Clean. Product. 2018, 201, 156-168.

27. Li, L.; Wu, W.; Giller, P.; O’Halloran, J.; Liang, L.; Peng, P.; Zhao, G. Life Cycle Assessment of a Highly Diverse Vegetable Multi-Cropping System in Fengqiu County, China. Sustainability 2018, 10, 983.

28. Matsuura, E.; Komatsuzaki, M.; Hashimi, R. Assessment of Soil Organic Carbon Storage in Vegetable Farms Using Different Farming Practices in the Kanto Region of Japan. Sustainability 2018, 10, 152.

29. Ugolini, R.C.E.; Trotti, F. Use of Fertilizers in Agriculture: Individual Effective Dose Estimate. Environments 2020, 7, 7.

30. Fanelli, R. The Spatial and Temporal Variability of the Effects of Agricultural Practices on the Environment. Environments 2020, 7, 33.

31. Krommydas, K.; Mavromatis, A.; Bletsos, F.; Roupakias, D. Suitability of CMS-based Interspecific Eggplant (Solanum melongena L.) Hybrids as Rootstocks for Eggplant Grafting. J. Agric. Ecol. Res. Int. 2018, 15, 1-15.

32. Xu, Q.; Hu, K.-L.; Li, J.; Han, H.; Yang, H.-F. Life Cycle Environmental Impact Assessment on Different Modes of Greenhouse Vegetable Production in the North China Plain. Huan Jing Ke Xue 2018, 39, 24802488. (In Chinese)

33. Plant Protection. Eggplant: Fertilizing Guide for Open Field and Greenhouse Cultivation (In Greek). Plant Protection 2019.

34. Barchi, L., Pietrella, M., Venturini, L., Minio, A., Toppino, L., Acquadro, A., et al. (2019). A chromosomeanchored eggplant genome sequence reveals key events in Solanaceae evolution. Sci. Rep. 9, 11769-11769. doi: 10.1038/s41598-019-47985-w

35. Barchi, L., Rabanus-Wallace, M. T., Prohens, J., Toppino, L., Padmarasu, S., Portis, E., et al. (2021). Improved genome assembly and pan-genome provide key insights on eggplant domestication and breeding. Plant J. 107, 579-596. doi: 10.1111/tpj.15313

36. CNCB-NGDC Members and Partners (2019). Database resources of the national genomics data center in 2020. Nucl. Acids Res. 48, D24-D33. 
37. Li, D., Qian, J., Li, W., Yu, N., Gan, G., Jiang, Y., et al. (2021). A high-quality genome assembly of the eggplant provides insights into the molecular basis of disease resistance and chlorogenic acid synthesis. Mol. Ecol. Resourc. 21, 1274-1286. doi: 10.1111/1755-0998.13321

38. Miyatake, K., Saito, T., Nunome, T., Yamaguchi, H., Negoro, S., Ohyama, A., et al. (2020). Fine mapping of a major locus representing the lack of prickles in eggplant revealed the availability of a 0.5-kb insertion/deletion for marker-assisted selection. Breed. Sci. 70, 438-448. doi: 10.1270/jsbbs.20004

39. +Wei, Q., Wang, J., Wang, W., Hu, T., Hu, H., and Bao, C. (2020). A high-quality chromosome-level genome assembly reveals genetics for important traits in eggplant. Horticult. Res. 7, 153-153. doi: 10.1038/s41438-020-00391-0

40. Zhang, F., Wang, H., Kalve, S., Wolabu, T. W., Nakashima, J., Golz, J. F., et al. (2019). Control of leaf blade outgrowth and floral organ development by LEUNIG, ANGUSTIFOLIA3 and WOX transcriptional regulators. New Phytol. 223, 2024-2038. doi: 10.1111/nph.15921

41. Zhang, L., Sun, H., Xu, T., Shi, T., Li, Z., and Hou, W. (2021). Comparative transcriptome analysis reveals key genes and pathways involved in prickle development in eggplant. Genes 12:341. doi: 10.3390/genes12030341

42. Zhou, N., Tang, K. X., Jeauffre, J., Thouroude, T., Lopez Arias, D., Foucher, F., et al. (2020). Genetic determinism of prickles in rose. Theor. Appl. Genet. 133, 3017-3035. doi: 10.1007/s00122-020-03652

43. Song, B. et al. Draft genome sequence of Solanum aethiopicum provides insights into disease resistance, drought tolerance, and the evolution of the genome. GigaScience 8, 1-16 (2019).

44. Barchi, L. et al. A chromosome-anchored eggplant genome sequence reveals key events in Solanaceae evolution. Sci. Rep. 9, 11769 (2019).

45. Vaser, R., Sovic, I., Nagarajan, N. \& Sikic, M. Fast and accurate de novo genome assembly from long uncorrected reads. Genome Res. 27, 737-746 (2017).

46. Gao, L., Gonda, I., Sun, H., Ma, Q., Bao, K., Tieman, D.M. et al. (2019) The tomato pan-genome uncovers new genes and a rare allele regulating fruit flavor. Nature Genetics, 51, 1044- 1051.

47. Dupin J, Matzke NJ, Särkinen T, Knapp S, Olmstead RG, Bohs L, Smith SD.. 2017. Bayesian estimation of the global biogeographical history of the Solanaceae. J Biogeogr. 44(4):887-899.

48. Letunic I, Bork P.. 2016. Interactive tree of life (iTOL) v3: an online tool for the display and annotation of phylogenetic and other trees. Nucleic Acids Res. 44(W1):W242-W245.

49. Antipov D, Korobeynikov A, Mclean JS, Pevzner PA. 2016. hybridSPAdes: an algorithm for hybrid assembly of short and long reads. Bioinformatics. 32(7):1009-1015.

50. Letunic I, Bork P. 2016. Interactive tree of life (iTOL) v3: an online tool for the display and annotation of phylogenetic and other trees. Nucleic Acids Res. 44(W1):W242-W245.

51. Khan AR, Park CE, Park GS, Seo YJ, So JH, Shin JH. 2015. The whole chlorolplast genome sequence of black nightshade plant (Solanum nigrum). Mitochondrial DNA. 28:1-2.

52. Raveendar S, Na YW, Lee JR, Shim D, Ma KH, Lee SY, Chung JW. 2015. The complete chloroplast genome of Capsicum annuum var. glabriusculum using Illumina sequencing. Molecules. 20:13080-13088.

53. Wu Z. 2015. The completed eight chloroplast genomes of tomato from Solanum genus. Mitochondrial DNA. 21:1-3.

54. Perrin, A., Varré, J.-S., Blanquart, S. \& Ouangraoua, A. ProCARs: Progressive Reconstruction of Ancestral Gene Orders. BMC Genomics 16(Supp1 5), S6 (2015).

55. Aubriot, X., Knapp, S., Syfert, M.M., Poczai, P. \& Buerki, S. (2018) Shedding new light on the origin and spread of the brinjal eggplant (Solanum melongena L.) and its wild relatives. American Journal of Botany, 105, 1175-1187. https://doi.org/10.1002/ajb2.1133.

56. Mat-Sulaiman, N.N.; Rafii, M.Y.; Duangjit, J.; Ramlee, S.I.; Phumichai, C.; Oladosu, Y.; Datta, D.R.; Musa, I. Genetic variability of eggplant germplasm evaluated under open field and glasshouse cropping conditions. Agronomy 2020, 10, 436.

57. Dempewolf, H.; Baute, G.; Anderson, J.; Kilian, B.; Smith, C.; Guarino, L. Past and future use of wild relatives in crop breeding. Crop Sci. 2017, 57, 1070-1082. 
58. Kaushik, P.; Prohens, J.; Vilanova, S.; Gramazio, P.; Plazas, M. Phenotyping of eggplant wild relatives and interspecific hybrids with conventional and phenomics descriptors provides insight for their potential utilization in breeding. Front. Plant Sci. 2016, 7, 677.

59. Gürbüz, N.; Uluişik, S.; Frary, A.; Frary, A.; Doğanlar, S. Health benefits and bioactive compounds of eggplant. Food Chem. 2018, 268, 602-610.

60. Musa, I.; Rafii, M.Y.; Ahmad, K.; Ramlee, S.I.; Md-Hatta, M.A.; Oladosu, Y.; Halidu, J. Effects of grafting on morphophysiological and yield characteristic of eggplant (Solanum melongena L.) grafted onto wild relative rootstocks. Plants 2020, 9, 1583.

61. BPGR. Descriptors for Eggplant. International Board for Plant Genetic Resources (IBPGR): Rome, Italy, 1990.

Available online: $\mathrm{https://www.bioversityinternational.org/fileadmin/user} \mathrm{upload/online} \mathrm{library/publications/}$ pdfs/401.pdf (accessed on 6 May 2021).

62. Sharma, S.; Sharma, A.; Katoch, V. Biotechnological interventions in eggplant (Solanum melongena L.). Hortic. Sci. Biotechnol. 2020, 95, 273-285.

63. Tani, E.; Kizis, D.; Markellou, E.; Papadakis, I.; Tsamadia, D.; Leventis, G.; Karapanos, I. Cultivardependent responses of eggplant (Solanum melongena L.) to simultaneous Verticillium dahliae infection and drought. Front. Plant Sci. 2018, 9, 1181.

64. Kumar, A.; Sharma, V.; Jain, B.T.; Kaushik, P. Heterosis Breeding in Eggplant (Solanum melongena L.): Gains and Provocations. Plants 2020, 9, 403. https://doi.org/10.3390/plants9030403

65. Vacher, M.; Small, I. Simulation of heterosis in a genome-scale metabolic network provides mechanistic explanations for increased biomass production rates in hybrid plants. NPJ Syst. Biol. Appl. 2019, 5, 1-10.

66. Barboza GE, Carrizo García C, Leiva González S (2019) Four new Species of Capsicum (Solanaceae) from the tropical Andes and an update on the phylogeny of the genus. PLoS ONE 14:

67. Bernau V, Barbolla LJ, McHale LK, Mercer KL (2020) Germination response of diverse wild and landrace chile peppers (Capsicum spp.) under drought stress simulated with polyethylene glycol. bio Rxiv preprint. https://doi.org/10.1101/2020.06.29.177386

68. Du H, Wen C, Zhang X, Xu X, Yang J, Chen B, Geng S (2019) Identification of a major QTL (qRRs-10.1) that confers resistance to Ralstonia solanacearum in pepper (Capsicum annuum) using SLAF-BSA and QTL Mapping. Int J Mol Sci 20:5887

69. Colonna V, D'Agostino N, Garrison E, Albrechtsen A, Meisner J, Facchiano A, Cardi T, Tripodi P (2019) Genomic diversity and novel genome-wide association with fruit morphology in Capsicum, from $746 \mathrm{k}$ polymorphic sites. Sci Rep 9:10067

70. Ashok KR, Chinnadurai M, Raj SV, Sanjeevikumar A (2019) Socio-economic Assessment of LMOs: An ex ante analysis of insect resistance and herbicide tolerance in maize and brinjal in Tamil Nadu. In: Socioeconomic impact assessment of genetically modi ed crops, Springer, Singapore, pp 101-120

71. Palraju M, Paulchamy R, Sundaram J (2018) Population genetic structure and molecular diversity of Leucinodes orbonalis based on mitochondrial COI gene sequences. Mitochondrial DNA A 29:1231-1239. https://doi.org/10.1080/24701394.2018.1436169

72. Rameash K, Sivaraj N, Babu BS, Chakrabarty SK (2015) Screening brinjal genotypes for resistance to shoot and fruit borer, Leucinodes orbonalis and analysing the geographic divergence of resistance through divagis. Bioscan 10:923-928.

73. Ou, S., \& Jiang, N. (2018). LTR_retriever: A highly accurate and sensitive program for identification of long terminal repeat retrotransposons. Plant Physiology, 176(2), 1410-1422. https://doi.org/10.1104/ pp.17.01310 
74. Yang, X., Zhang, Y., Cheng, Y., \& Chen, X. (2019). Transcriptome analysis reveals multiple signal network contributing to the Verticillium wilt resistance in eggplant. Scientia Horticulturae, 256, 108576. https:// doi.org/10.1016/j.scienta.2019.108576

75. Youn, Y., Jeon, S. H., Jin, H. Y., Che, D. N., Jang, S. I., \& Kim, Y. S. (2019). Chlorogenic acid-rich Solanum melongena extract has protective potential against rotenone-induced neurotoxicity in PC-12 cells. Journal of Food Biochemistry, 43(11), e12999. https://doi. org/10.1111/jfbc.12999

76. Zhou, H., Lin-Wang, K., Wang, F., Espley, R. V., Ren, F., Zhao, J., Ogutu, C., He, H., Jiang, Q., Allan, A. C., \& Han, Y. (2019). Activator-type R2R3- MYB genes induce a repressor-type R2R3-MYB gene to balance anthocyanin and proanthocyanidin accumulation. New Phytologist, 221(4), 1919-1934. https://doi.org/10.1111/nph.15486

77. Hu W.M., Kingsbury K., Mishra S., DiGennaro P. A comprehensive transcriptional profiling of pepper responses to root-knot nematode. Genes. 2020;11:1507. doi: 10.3390/genes11121507.

78. Zhou Y., Zhao D., Shuang L., Xiao D., Xuan Y., Duan Y., Chen L., Wang Y., Liu X., Fan H., et al. Transcriptome analysis of rice roots in response to root-knot nematode infection. Int. J. Mol. Sci. 2020;21:848. doi: 10.3390/ijms21030848.

79. He YJ, Chen H, Zhou L, Liu Y, Chen HY (2019). Comparative transcription analysis of photosensitive and non-photosensitive eggplants to identify genes involved in dark regulated anthocyanin synthesis. BMC Genomics 20:678.

80. Huang J, Xing M, Li Y, Cheng F, Gu H, Yue C, Zhang Y (2019). Comparative transcriptome analysis of the skin-specific accumulation of anthocyanins in black peanut (Arachis hypogaea L.). Journal of Agricultural and Food Chemistry 67:1312-1324.

81. Toppino L, Barchi L, Mercati F, Acciarri N, Perrone D, Martina M, ... Rotino GL (2020). A new intraspecific and high-resolution genetic map of eggplant based on a RIL population, and location of QTLs related to plant anthocyanin pigmentation and seed vigour. Genes 11:745.

82. Zhang SM, Zhang AD, Wu XX, Zhu ZW, Yang ZF, Zhu YL, Zha DS (2019). Transcriptome analysis revealed expression of genes related to anthocyanin biosynthesis in eggplant (Solanum melongena L.) under high-temperature stress. BMC Plant Biology 19:387.

83. Wang N, Liu W, Zhang T, Jiang S, Xu H, Wang Y, ... Chen X (2018). Transcriptomic analysis of redfleshed apples reveals the novel role of MdWRKY11 in flavonoid and anthocyanin biosynthesis. Journal of Agricultural and Food Chemistry 66:7076-7086.

84. Kaushik, P., 2020a. Transcriptome Analysis of the Eggplant Fruits Overexpressing a Gene of Chlorogenic Acid Pathway. bioRxiv.

85. Kaushik, P., 2020b. Characterization of Cultivated Eggplant and its Wild Relatives Based on Important Fruit Biochemical Traits. Pakistan Journal of Biological Sciences: PJBS 23, 1220-1226.

86. Kaushik, P., 2019a. Standardisation of an Agroinfiltration Protocol for Eggplant Fruits and Proving its Usefulness by Over-expressing the SmHQT Gene.

87. Kaushik, P., 2019b. Line $\$ \backslash$ times $\$$ Tester analysis for morphological and fruit biochemical traits in eggplant (Solanum melongena L.) using wild relatives as testers. Agronomy 9, 185. 
88. Kaushik, P., 2019c. Genetic analysis for fruit phenolics content, flesh color, and browning related traits in eggplant (Solanum melongena). International journal of molecular sciences 20, 2990.

89. Kaushik, P., 2019d. Application of conventional, biotechnological and genomics approaches for eggplant (solanum melongena. L). Breeding with a focus on bioactive phenolics (PhD Thesis). Universitat Politècnica de València.

90. Kaushik, P., Gramazio, P., Vilanova, S., Raigón, M.D., Prohens, J., Plazas, M., 2017. Phenolics content, fruit flesh colour and browning in cultivated eggplant, wild relatives and interspecific hybrids and implications for fruit quality breeding. Food Research International 102, 392-401. 